RIIT Vol.IX. No.4. 2008 319-328, ISSN 2594-0732,

FI-UNAM (artículo arbitrado)

DOI: http://dx.doi.org/10.22201/fi.25940732e.2008.09n4.024

\title{
Inter-Vehicular Communications Using Wireless Ad-Hoc Networks
}

\section{Comunicación inter-vehicular utilizando redes ad-hoc inalámbricas}

\author{
R. Aquino-Santos \\ College of Telematics, University of Colima. \\ E-mail:aquinor@ucol.mx \\ V. Rangel-Licea \\ Department of Engineering in Telecommunications, \\ Faculty of Engineering, UNAM. \\ E-mail:victor@fi-b.unam.mx \\ A. Edwards \\ College of Telematics, University of Colima. \\ E-mail:arted@ucol.mx
}

(Recibido: febrero de 2007; aceptado: enero de 2008)

\begin{abstract}
This paper proposes a new routing algorithm to facilitate communication in highly mobile wireless ad-hoc networks for motorway environments with no physical infrastructure which undergo frequent topological changes. This new reactive routing algorithm for inter-vehicular communication is based on location information in which the source node ascertains the position of its communication partner before it initiates communication. The advantage of this algorithm is that it does not require global knowledge to send information between transmitter-receiver pairs. Instead, this algorithm requires knowledge of the relative positions of its neighbor nodes and the position of the destination.

This paper discusses simulations of 250 vehicles driving on a six-lane circular highway using Location Routing Algorithm with Cluster-Based Flooding (LORA-CBF). Highway vehicular mobility is simulated by a microscopic traffic model, developed in OPNET, to evaluate the performance of the LORA-CBF and Greedy Perimeter Stateless Routing (GPSR) algorithms in terms of Route Discovery Time (RDT), End-to-End Delay (EED), Routing Overhead (RO), Routing Load (RL) and Delivery Ratio (DR).
\end{abstract}

Keywords: Unicast routing, multi-hop wireless networks, inter-vehicular data exchange, ad-hoc networks, location routing algorithm with cluster-based flooding.

\section{Resumen}

Este trabajo presenta un nuevo algoritmo de enrutamiento que permite la comunicación inter-vehicular en redes ad-hoc, las cuales carecen de infraestructura fija y sufren frecuentes cambios topológicos. Este nuevo algoritmo es reactivo y adecuado para la comunicación inter-vehicular y su estrategia de enrutamiento emplea el sistema global GPS, donde el nodo originador del mensaje solicita la posición del nodo destino antes de iniciar la comunicación. La ventaja de este algoritmo es que no requiere un conocimiento global de la red para enviar datos entre el transmisor-receptor; sólo necesita conocer las posiciones relativas de los nodos vecinos y 
la posición del destino para reducir significativamente la inundación de paquetes de control.

Este trabajo simula el comportamiento de 250 vehículos sobre una autopista de tres carriles por dirección, utilizando el algoritmo de enrutamiento geográfico con difusión basada en grupos (LORA-CBF). La movilidad de los vehículos utiliza un algoritmo microscópico que se simula en OPNET. Se compara LORA-CBF con "Greedy Perimeter Stateless Routing" (GPSR) en términos del tiempo de descubrimiento de rutas (RDT), retardo punto a punto (EED), y Sobre-encabezado de enrutamiento para evaluar el algoritmogeográficocon difusión basadaen grupos.

Descriptores: Enrutamiento con dirección única, redes inalámbricas multisalto, intercambio de datos entre vehículos, redes ad hoc, enrutamiento por localización con difusiónbasadaengrupos.

\section{Introduction}

Over the past quarter century, the automobile industry has increasingly used computer technologies to provide greater safety, reliability and passenger enjoyment. Some of these innovations include air bag technology, Global Positioning System (GPS), self-diagnostic hardware and software, and entertainment systems. Future developments in automobile manufacturing will increasingly include ubiquitous wireless ad hoc network technology to provide improved communication, safety and traffic control.

In order to avoid communication costs and guarantee the low delays needed to efficiently exchange data between cars, Inter-Vehicle Communication (IVC) systems, based on wireless ad-hoc networks, represent a promising option for future road communication needs. IVC permits vehicles to organize themselves locally in ad-hoc mode to consecutive vehicles traveling within a specific radio transmission range, using a one-hop strategy. In the future, IVC systems will provide multi-hop communication, using "relay" vehicles that are physically located between a specific senderreceiver pair. Routing algorithms in mobile ad-hoc wireless networks can be categorized into two different categories: non-positional algorithms and positional algorithms.

Non-positional algorithms can be classified as proactive (table-driven), reactive (on-demand), or hybrid. Proactive, or table-driven algorithms, periodically update the location information of their nodes, making routes immediately available when needed. The disadvantage of these algorithms, however, is that they require additional bandwidth to periodically transmit location traffic. The increased transmission of location traffic packets, however, can result in significant network congestion because each individual node must maintain the necessary routing information and is responsible for propagating topology updates in response to instantaneous changes in network connectivity (Perkins, 2000). Important examples of non-positional protocols include Optimized Link State Routing (OSLR) (Clausen et al., 2003) and Topology Dissemination Based on Reverse Path Forwarding (TBRPF) (Ogier et al., 2004).

These two protocols record the routes for all possible destinations in the ad-hoc network, resulting in minimal initial delay (latency) when communicating with arbitrarily selected destination. Such protocols are also called proactive because they store route information before it is actually needed and are table driven because the information is available as part of well-maintained tables.

On the other hand, on-demand, or reactive protocols, acquire routing information only as needed. Reactive routing protocols often use less bandwidth for maintaining route tables. The disadvantage of these protocols, however, is that the Route Discovery (RD) time for many applications can substantially increase. Most applications may suffer delay when they start because a destination route must be acquired before communication can actually begin. On-demand protocols must realize a route discovery process before the first data packet can be sent, resulting in reduced control traffic overhead at the cost of increased latency in finding the route destination (Zou et al., 2002). Examples of reactive, or on-demand protocols, include Ad-Hoc On-Demand Distance Vector (AODV) routing (Perkins et al., 2003), and Dynamic source Routing (DSR) algorithms (Johnson et al., 2004). 
DOI: http://dx.doi.org/10.22201/fi.25940732e.2008.09n4.024

R. Aquino-Santos, V. Rangel-Licea, A. Edwards

A protocol that combines both proactive and reactive approaches is called a hybrid (Schaumann, 2002). The most popular protocol in this category is the Zone Routing Protocol (ZRP).

Scalability represents the principal disadvantage of proactive and reactive routing algorithms in highly mobile environments. A second disadvantage is their very low communication throughput, which sometimes results in a potentially large number of retransmissions (Mauve et al., 2001).

To overcome these limitations, however, several new types of routing algorithms that employ geographic position information have been developed, including: Location-Aided Routing (LAR) (Ko and Vaidya, 1998), Distance Routing Effect Algorithm for Mobility (DREAM) (Basagni et al., 1998), Grid Location Service (GLS) (Li et al., 2000) and Greedy Perimeter Stateless Routing for Wireless Networks (GPSR) (Karp and Kung, 2000).

\section{Reactive Location-Based Routing Algorithm With Cluster-Based Flooding (LORA-CBF)}

The advantage of using positional information in vehicular ad-hoc wireless networks (VANET) is that routing can be fully dynamic and distributed. Furthermore, fewer error packets are transmitted in dynamic ad-hoc networks as compared to non-positional algorithms, which is possible because the node only needs to maintain information for one-hop neighbors and the position of the destination.

This paper proposes a reactive location routing algorithm with cluster-based flooding for inter-vehicle communication (LORA-CBF) to deal with the increasing number of vehicles in circulation (Camp et al., 2002).

The algorithm we have developed inherits the properties of reactive and hierarchical routing algorithms, but has the advantage of acquiring routing information only as needed. First of all, LORA-CBF improves traditional routing algorithms that are based on non-positional routing by using location information provided by GPS. Secondly, it minimizes flooding of its Location Request (LREO) packets by means of gateway flooding, which is directive for traffic control and uses only selected nodes, called gateway nodes, to diffuse LREO messages.

The purpose of a gateway node is to minimize the flooding of broadcast messages in the network by reducing duplicate retransmissions in the same region.
Member nodes are converted into gateways when they receive messages from more than one cluster-head. All the members in the cluster read and process the packet, but do not retransmit the broadcast message. This technique significantly reduces the number of retransmissions in a flooding or broadcast procedure in dense networks. Therefore, only gateway nodes retransmit packets between clusters in what is called a hierarchical organization. Moreover, gateways only retransmit a packet from one gateway to another in order to minimize unnecessary retransmissions, and only if the gateway belongs to a different cluster-head. To avoid synchronization of transmissions (Jacquet, 2002), (Floyd and Jacobson, 1994) the forwarding of individual packets is randomly delayed.

Several researches have investigated cluster-based flooding strategies for routing in wireless ad-hoc networks (Mitelman and Zaslavsky, 1999), (Krishna et al., 1997), (Das et al., 1997), (Sivakumar et al., 1998), (Chiang et al., 1997). The main contribution of our work is the rebroadcast and gateway selection mechanism we have developed. We have implemented a re-broadcast strategy, where only gateways that belong to different cluster-heads re-broadcast the location request packets, thus improving the routing overhead in dense networks (Santos et al., 2004).

\section{Microscopic Traffic Models}

According to (Hoogendoor and Bovy, 2001) and (Festa et al., 2001), vehicular traffic models may be categorized into four level-of-detail classifications: sub-microscopic, microscopic, mesoscopic and macroscopic. Submicroscopic models describe the characteristics of individual vehicles in traffic flow and the operation of specific parts (sub-units) of the vehicle (e.g., changing gears, braking, etc.). Microscopic models simulate behavior and interaction among interacting drivers. Mesoscopic models represent transportation systems and analyze groups of drivers with homogeneous behavior. Finally, macroscopic models describe traffic at a high level of aggregation as a flow without distinguishing its basic parts (Cvetkovski and Gavrilovska, 1998). Macroscopic models are used to study traffic flow in road networks by evaluating variables such as density, flow and average speed.

This work analyses MIMIC, INTEGRATION, AIMSUM, MITSIM, VISSIM and SIMONE 2000 (Logghe, 2003), six of the most important microscopic traffic models, which are all based on safe-distance, 
stimulus-response and psycho-physiological car-following models (Klar et al., 1996).

From the models included in this study, VISSIM contains the greatest number of parameters and AIMSUM has the fewest. The major drawback of the MIMIC, INTEGRATION and VISSIM models is their calibration parameters, which must be dynamically determined during the simulation period. The AIMSUM model has the disadvantage that it does not clearly define how to estimate the maximum deceleration rate of the $n-1$ vehicle and the difficulty with MITSIM is that it bases its acceleration or deceleration rate on too many speed intervals.

The Simone 2000 traffic simulation model is the most suitable for the simulation scenarios we have selected for our investigation, as its behavior is based on both distance and longitudinal controllers. In addition, it incorporates the effects of positive or negative relative speeds. Consequently, for these two principal reasons, we have chosen Simone 2000 to simulate vehicle mobility in freeway and urban settings.

\section{A Comparison of the Lora-Cbf and Gpsr Algorithms on a Multi-Lane Circular Dual Motorway Representative of a Six Lane Motorway Driving}

This section will compare a Location-Based Routing Algorithm with Cluster-Based Flooding (LORA-CBF) we developed with a very popular position-based routing algorithm called GPSR (Greedy Perimeter Stateless Routing). Results demonstrate that at an average speed of $42 \mathrm{~m} / \mathrm{s}(150 \mathrm{~km} / \mathrm{h})$, the lack of a predictive algorithm and global knowledge position in GPSR significantly deteriorates its performance.

The GPSR algorithm was simulated on the same circular dual motorway scenario with 250 vehicles at a relative speed of $84 \mathrm{~m} / \mathrm{s}(300 \mathrm{~km} / \mathrm{h})$. Results show that without a predictive algorithm and GPS, it is impossible to communicate between a source-destination pair that is located more that two hops apart. Our intention here is to show that employing a predictive algorithm will significantly improve communication on a motorway.

We have implemented the same short-term predictive algorithm used in LORA-CBF (Santos et al., 2004) and the same physical and MAC layer in GPSR.

We have also used the same measurements to analyze and compare the performance of LORA-CBF and GPSR.

\section{Simulation Metrics}

We have chosen to compare the performance of the LORA-CBF and GPSR algorithms in large-scale ad-hoc networks using the most common metrics, including:

Route discovery time (Latency): The time the source node must wait before sending its first data packet.

Average end-to-end delay of data packets: The possible delays caused by buffering packets during route discovery, queuing at the interface queue, retransmission delays at the MAC layer, propagation and transfer times. Routing load: The ratio of routing packets to data packets transmitted. The latter includes only the data packets finally delivered to the destination and excludes those that are dropped. The transmission of each hop is counted once for both routing and data packets. This provides an idea of network bandwidth consumed by routing packets with respect to "useful" data packets.

Routing overhead: The total number of routing packets transmitted during the simulation. For packets sent over multiple hops, each transmission of the packet (in each hop) counts as one retransmission.

Packet delivery ratio: The ratio between the data packets actually delivered to the destination and the number of data packets sent by the sender. The main reason data packets are dropped in route is because the next hop link is broken when the data packet is ready to be transmitted.

\section{Communication Model}

The model developed for evaluating the proposed routing protocols was implemented in OPNET as illustrated in figure 1. Because one of the goals of the simulation is to compare the performance of each routing protocol, our traffic sources maintain a constant bit rate (CBR). When defining the parameters of the communication model, we experimented with $1 \mathrm{Mbps}$ and $11 \mathrm{Mbps}$ data rates, each with a constant packet size of 1448 bytes, similar to the packets used in the test-bed (Toh et al., 2002). The communication between the source and destination is peer-to-peer and it is initiated at uniformly distributed times of between 1-5 seconds. LORA-CBF was provided five seconds, even though its cluster formation mechanism requires less than two seconds, to guarantee a steady-state network. The values represented in figures 2 to 6 depict the results of 30 simulations with a margin of error of less than $10 \%$ in most of the parameters analyzed, (figure 1). 


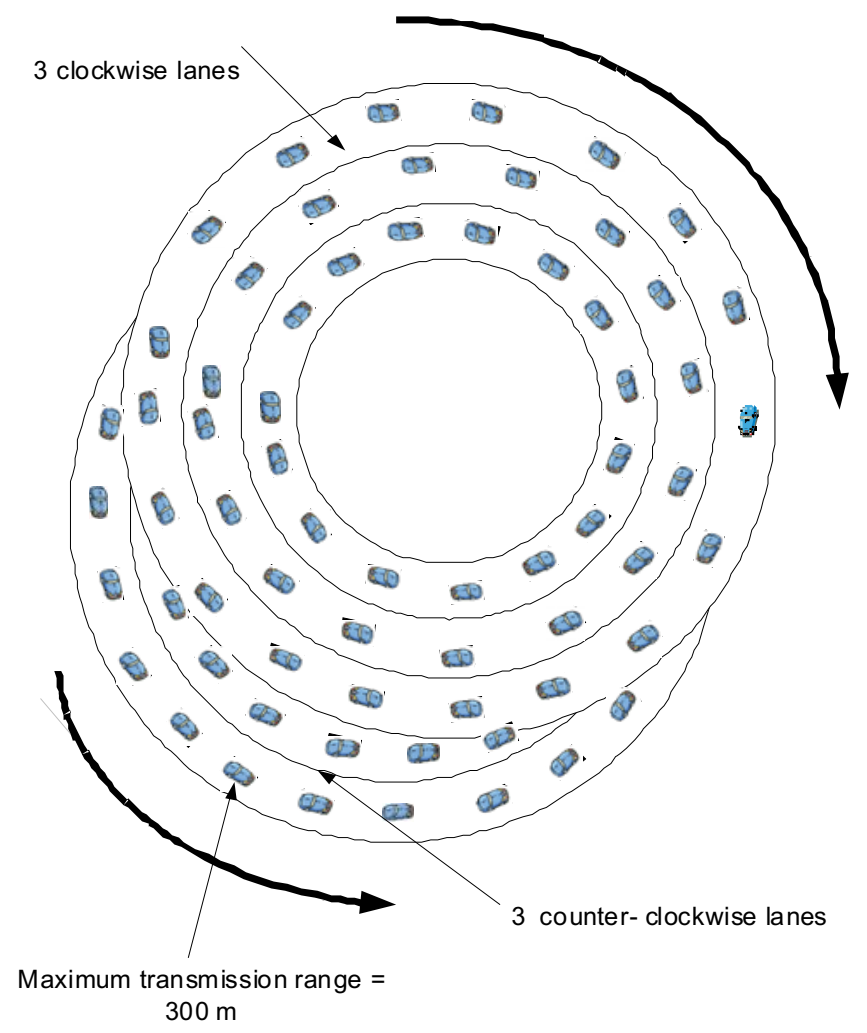

Figure 1

\section{Physical and Medium Access Mechanism}

Antenna gain, transmission power, and receiver sensitivity were chosen to approximate the Enterasys IEEE 802.11 b WLAN direct sequence spread spectrum ratio. A transmission range of $300 \mathrm{~m}$., which is consistent with current $802.11 \mathrm{~b}$ Wireless LAN and $5 \mathrm{dBi}$ gain car-mounted antennas, was also selected.

The IEEE 802.11b Distributed Coordination Function (DCF), designed to use both virtual and physical carrier sense mechanisms to reduce the probability of collisions due to hidden terminals, was used as the medium access control protocol.

\section{Results by Simulations Using OPNET}

Figure 2 represents the delivery ratio of GPSR and LORA-CBF. LORA-CBF improves the communication of GPSR after the fifth hop at a data rate of $1 \mathrm{Mbps}$; both algorithms, however, behave similarly at a data rate of $11 \mathrm{Mbps}$. In general, both algorithms show similar results for short hops because they use the same forwarding mechanism (greedy forwarding), but the clustering mechanism used in LORA-CBF is better for longer hops. Figure 3, which shows End-to-End Delay, reveals that GPSR and LORA-CBF have similar EED because both algorithms use the same forwarding mechanism. Figure 4 shows that LORA-CBF has a higher routing overhead at a data rate of $11 \mathrm{Mbps}$ than GPSR at the same data rate because of the increased number of control packets. On the other hand, at a data rate of $1 \mathrm{Mbps}$, LORA-CBF begins with a slightly higher routing overhead than GPSR. However, at a distance of 5 hops $(1500 \mathrm{~m})$, both algorithms have exactly the same routing overhead. At greater distances, LORA-CBF has a lower routing overhead than GPSR because GPSR suffers from spatial diversity. Figure 5 represents the route discovery time. Both algorithms show similar behavior at a data rate of $11 \mathrm{Mbps}$, however, GPSR has a greater route discovery time a data rate of $1 \mathrm{Mbps}$. Because of its limited spatial diversity, packet collisions are significantly more frequent with GPSR. On the other hand, LORA-CBF reduces the route discovery time because of its cluster-based flooding mechanism. The routing load is shown in figure 6. Again, with a data rate of 11 Mbps, LORA-CBF has a slightly higher routing load 
than GPSR, and at a data rate of 1 Mbps, LORA-CBF begins with a slightly higher routing load than GPSR. At five hops (1500 m), however, both algorithms have the same routing load. At distances greater than 1500 m, LORA-CBF has a lower routing load than GPSR. Again, more collisions occur with GPSR, resulting in an increase routing load, because of its spatial diversity.

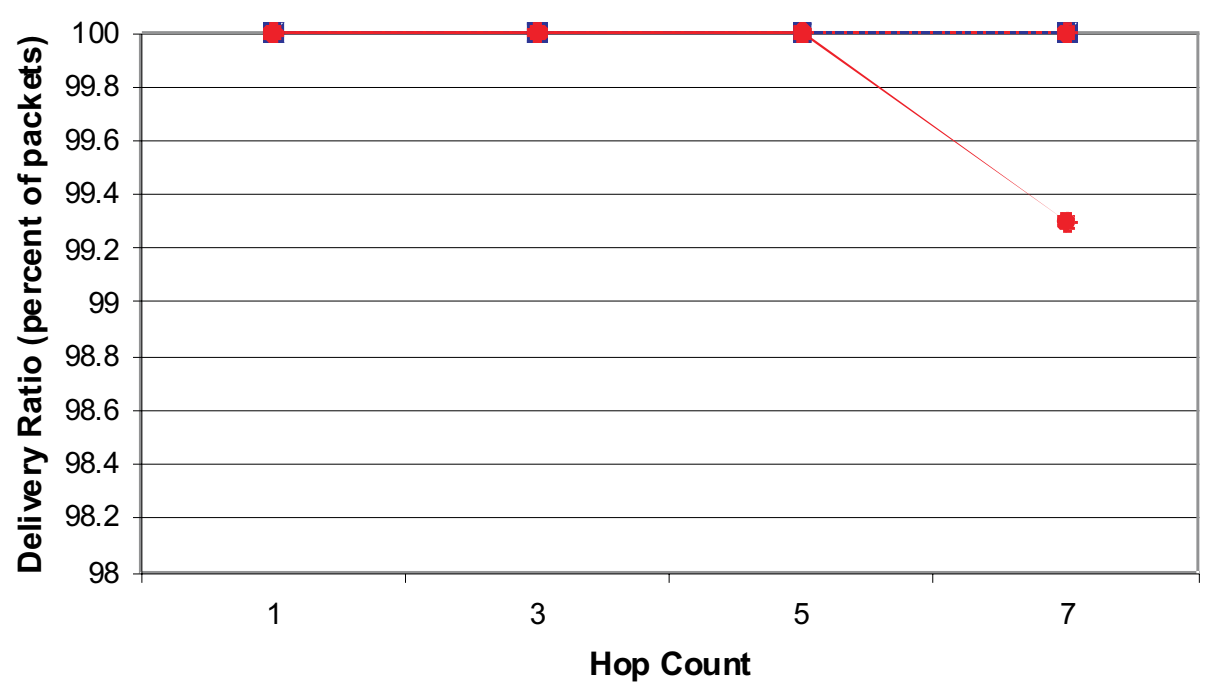

$\begin{array}{ll}- \text { LORA_CBF Motorway (1 Mbps) } & \text { LORA_CBF Motorway (11 Mbps) } \\ -\rightarrow \text { GPSR Motorway (1 Mbps) } & \text { - GPSR Motorway (11 Mbps) }\end{array}$

Figure 2

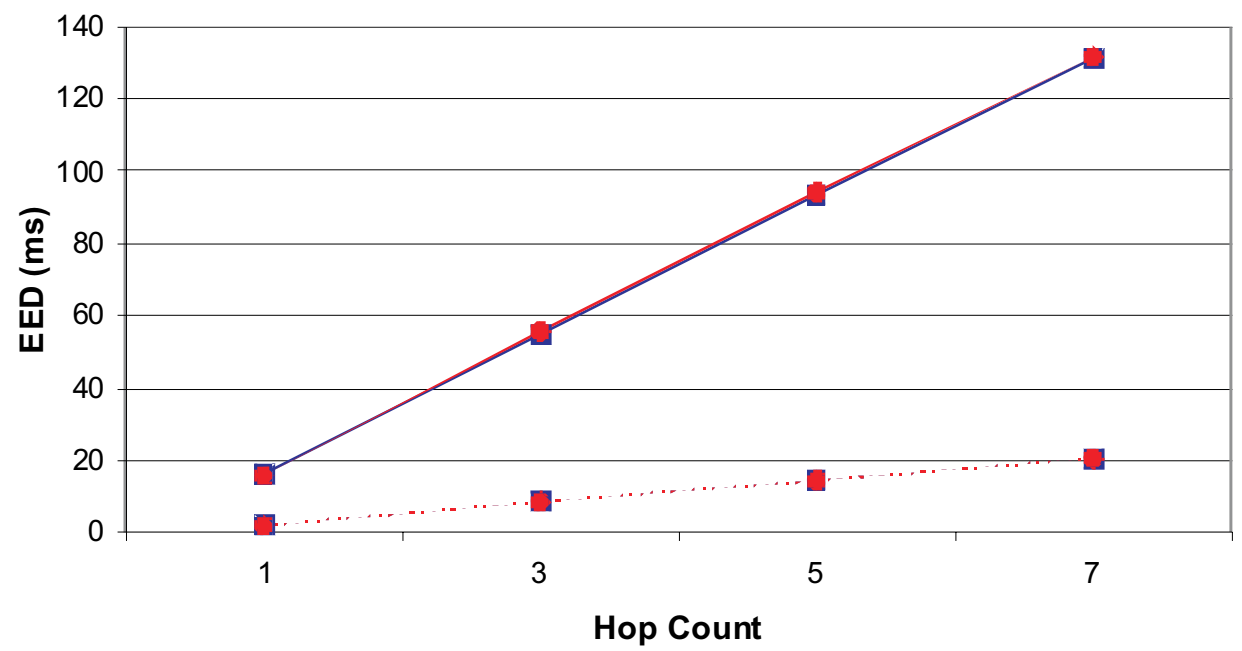

\begin{tabular}{|lc|}
\hline- LORA_CBF Motorway (1 Mbps) & $-\cdot \cdot \cdots$ LORA_CBF Motorway (11 Mbps) \\
- GPSR Motorway (1 Mbps) & GPSR Motorway (11 Mbps) \\
\hline
\end{tabular}

Figure 3 
DOI: http://dx.doi.org/10.22201/fi.25940732e.2008.09n4.024

R. Aquino-Santos, V. Rangel-Licea, A. Edwards

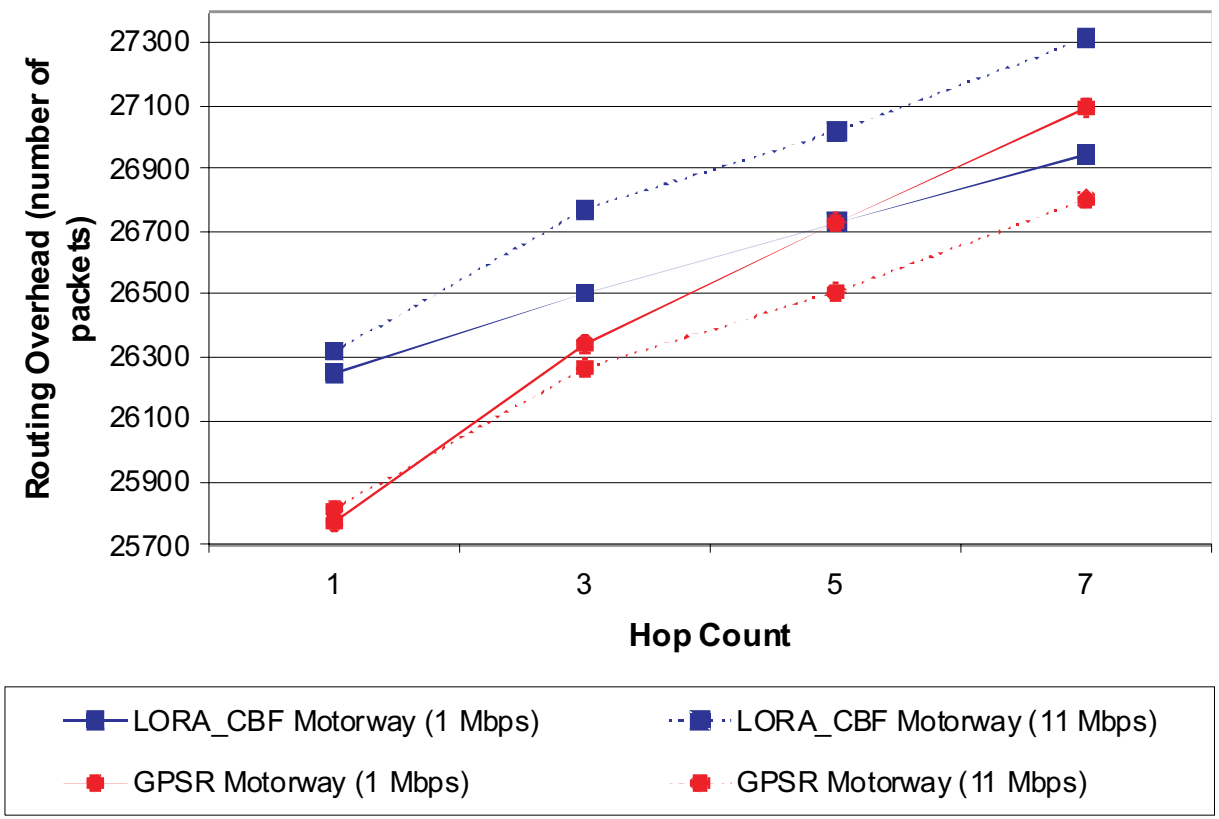

Figure 4

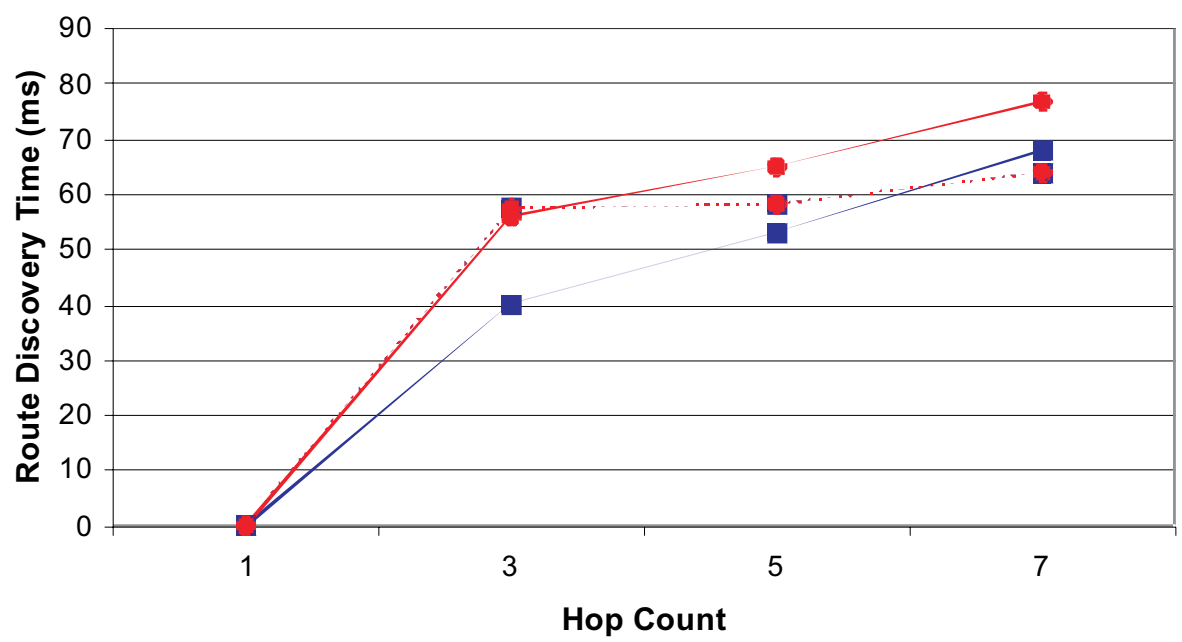

- LORA_CBF Motorway (1 Mbps)

- GPSR Motorway (1 Mbps)
LORA_CBF Motorway (11 Mbps)

- GPSR Motorway (11 Mbps)

Figure 5 

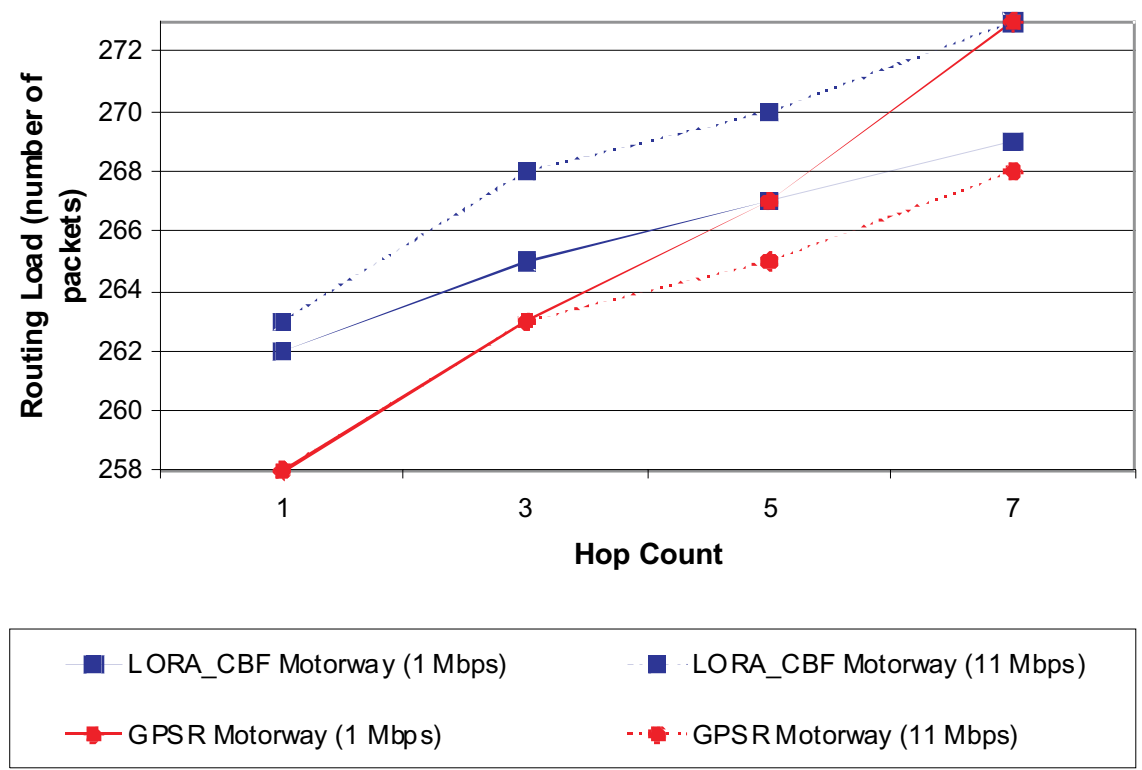

Figure 6

\section{Conclusions}

This paper has presented research results of a simulation that considers the mobility involved in typical motorway traffic scenarios of a very large network with a total of two hundred and fifty nodes. Controlling the data rate, transmission range, and velocity of the vehicular nodes, we have compared end to end delay, route discovery time, routing overhead, routing load and the delivery ratio between LORA-CBF and Greedy Perimeter Stateless Routing (GPSR).

Results indicate that GPSR can be improved by a short-term predictive algorithm to enhance its performance at higher speeds. Also, GPSR and LORA-CBF behave similarly when employing our short-term predictive algorithm, as both algorithms employ the same greedy forwarding and neighbor sensing mechanisms. In summary, the main difference between these two algorithms is found in the hierarchical architecture in LORA-CBF. This hierarchical architecture requires less route discovery time and a lower deliver ratio, but increases the routing overhead and general overhead, as well as routing load.

\section{Acknowledgements}

Our thanks to the Dirección General de Asuntos del Personal Académico of UNAM, for the support and financing for the projects PAPIIT No IN104907 and PAPIMEPE103807

\section{References}

Basagni S., Chalamtac I. Syrotiuk V. A Distance Routing Effect Algorithm for Mobility (DREAM). MOBICOM 98. Dallas Texas, USA. 1998.

Camp T., Boleng J. and Wilcox L. Location Information Services in Mobile Ad Hoc Networks. International Communication Conference (ICC), 2002.

Chiang Ch., Wu H.K., Liu W. and Mario G. Routing in Clustered Multihop, Mobile Wireless Networks with Fading Channel. The IEEE Singapore International Conference on Networks, pp 197-211, 1997.

Clausen T., Jacket P., Laouiti A., Minet P., Muhlethaler P., Qayyum A. and Viennot L. Optimized Link State Routing Protocol (OLSR) [on line]._2003. Available on: http://ietf.org/rfc/rfc3626.txt Request for Comments (Work in Progress).

Cvetkovski B. and Gavrilovska L. A Simulation of a Mobile Highway Traffic. IEEE VTC. 1998.

Cvetkovski B. and Gavrilovska L. A Simulation of a Mobile Traffic on a Highway. Series Electronics and Energetics, 11(1):57-70. 1998.

Das B., Sivakumar R. and Bharghavan V. Routing in Ad Hoc Networks Using a Spine. Proceedings in International Conference in Computer and Communication Networks, 1997. 
DOI: http://dx.doi.org/10.22201/fi.25940732e.2008.09n4.024

R. Aquino-Santos, V. Rangel-Licea, A. Edwards

Festa D., Longo G., Mazzulla G. and Musolino G. Experimental Analysis of Different Simulation Models for Motorway Traffic Flow. Proceedings of the IEEE Intelligent Transportation Systems Conference, 2001.

Floyd S. and Jacobson V. The Synchronization of Periodic Routing Messages. IEEE/ACM Transaction on Networking, 2(2):122-136, 1994.

Jacquet P., Laouiti A., Minet P. and Viennot L. Performance of Multipoint Relaying in Ad-Hoc Mobile Routing Protocols. Networking, Pise (Italy). 2002.

Johnson D., Maltz D., Hu Yih-Ch. The Dynamic Source Routing Protocol for Mobile Ad Hoc Networks (DSR) [on line], 2004. Available on: http://www.ietf.org/internet-drafts/draft-ietf-man et-dsr-10.txt

IETF Internet Draft (Work in Progress).

Hoogendoom S., Bovy P. State-of-the-Art of Vehicular Traffic Flow Modelling. Special Issue on Road Traffic Modelling and Control. Journal of System and Control Engineering. Pp. 283-303, 2001.

Karp B., Kung H. GPSR: Greedy Perimeter Stateless Routing for Wireless Networks. Proceedings of the 6th Annual ACM/IEEE International Conference on Mobile Computing and Networking (MobiCom 2000).

Klar A., Kühne R. and Wegener R. Mathematical Models for Vehicular Traffic. Surveys on Mathematics for Industry, 6:215-239, 1996.

Ko Y.B. and Vaidya N. Location-Aided Routing (LAR) in Mobile Ad Hoc Networks. Proceedings of the 4th annual ACM/IEEE International Conference on Mobile Computing and Networking, pp 66-75, 1998.

Krishna P., Vaidya N., Chatterjee M. and Pradhan D. A Cluster-Based Approach for Routing in Dynamic Networks. ACM SIGCOMM. Computer Communication Review. Pp. 49-65. 1997.

Li J., Jannotti J., De Couto D., Karger D. and Morris R. A Scalable Location Service for Geographic Ad Hoc Routing. ACM Mobicom 2000, Boston, MA. 2000.

Logghe S. Dynamic Modelling of Heterogeneous Vehicular Traffic. (Ph. D. Thesis). K.U. Leuven, Belgium. 2003.

Mauve M., Widmer J. and Hartenstein H. (2001). A Survey on Position-Based Routing in Mobile Ad-Hoc Networks. IEEE Network Magazine, 15(6): 30-39.

Mitelman, Boris. Zaslavsky, Arkady. Link State Routing Protocol with Cluster Based Flooding for
Mobile Ad-hoc Computer Networks. Proceedings of the Workshop on Computer Science and Information Technologies CSIT'99. 1999.

Ogier R., Lewis M. and Teplin F. Topology Dissemination based on Reverse-Path Forwarding (TBRPF) [on line], 2004. Available on:

http://www.ietf.org/rfc/rfc3684.txt Request for Comments (Work in Progress).

Perkins C. Ad Hoc Networking. Addison Wesley. 2000.

Perkins C., Belding-Royer E. and Das S. Ad Hoc On-Demand Distance Vector (AODV) Routing, 2003. Available on:

http://www.ietf.org/rfc/rfc3561.txt

Request for Comments (Work in Progress).

Santos R., Edwards R., Seed L. and Edwards A. A Location-Based Routing Algorithm for Vehicle to Vehicle Communication (13 ${ }^{\text {th }}, 2004$, Chicago IL, USA). IEEE International Conference on Computer Communication and Networks (ICCCN 2004), October, pp.11-15.

Schaumann Jan. Analysis of the Zone Routing Protocol [on line], 2002. Available on: http:///www.netmeister.org/misc/zrp/pdf

Sivakumar R., Das B. and Bharghavan V. Spine Routing in Ad Hoc Networks. ACM/Baltzer Cluster Computing Journal. 1998.

Toh C.K., Delwar M. and Allen D. Evaluating the Communication Performance of an Ad-Hoc Wireless Network. IEEE Transaction on Wireless Communication, 1(3), 2002.

Zou X., Ramamurthy B. and Magliveras S. Routing Techniques in Wireless Ad Hoc Networks-Classification and Comparison. Proceedings of the Sixth World Multiconference on Systemics, Cybernetics and Informatics, SCI. 2002. 
DOI: http://dx.doi.org/10.22201/fi.25940732e.2008.09n4.024

Inter-Vehicular Communications Using Wireless Ad-Hoc Networks

\section{About the authors}

Raúl Aquino-Santos. Received his MS degree in Telecommunications from the Centre for Scientific Research and Higher Education in Ensenada, Mexico in 1990. He holds a PhD from the Department of Electrical and Electronic Engineering of the University of Sheffield, England. His current research interests include wireless and sensor networks.

Victor Rangel-Licea. Received the B. Eng (Hons.) degree in Computer Engineering in the Engineering Faculty from the "Universidad Nacional Autónoma de México (UNAM)", Mexico in 1996 and the M.Sc. in Telematics from the University of Sheffield, U.K. in 1998. He holds a Ph.D. from the Centre for Mobile Communication Research, EEE Department, at the University of Sheffield, U.K. His research interests include modeling, design and analysis of CATV and wireless networks, QoS over IP and communication protocols. Victor Rangel is member of the IEEE.

Arthur Edwards. Is a Senior Professor at the College of Telematics of the University of Colima, where he is involved in developing educational software. His primary fields of interest include Usability Engineering and mobile learning. 